\title{
MODELING OF HEAT TRANSFER IN TUBES WITH TURBULENCE IN THE TRANSITION TO TURBULENT FLOW
}

\begin{abstract}
Аннотация. В статье проанализированы основные аспекты математического моделирования интенсифицированного теплообмена при турбулентном течении в трубах с турбулизаторами с применением четырёхслойной модели турбулентного пограничного слоя в зависимости от числа Прандтля. Показано преимущество закона «четвёртой» степени для больших чисел Прандтля для расчёта теплообмена в трубах с турбулизаторами; показано, что для труб с турбулизаторами коэффициент пропорииональности в этом законе значительно выше, чем в гладких трубах, что указывает на повыменный уровень турбулентности в них на границе вязкого и буферного подслоёв. Результаты расчёта теплообмена при больших числах Прандтля показали, что относительньй теплообмен с увеличением числа Прандтля увеличивается довольно незначительно, особенно после $\operatorname{Pr}>10^{2}$; после $\operatorname{Pr}>10^{3}$ он почти стабилизируется.
\end{abstract}

Ключевые слова: моделирование математическое; теплообмен; интенсификачия; турбулентный; труба; течение; турбулизатор; четырёхслойныгй, пограничный слой; критерий Прандтля.

Abstract. The main aspects of mathematical modeling of intensified heat transfer in turbulent flow in pipes with turbulators with the use of a four-layer model of a turbulent boundary layer are analyzed in the article, depending on the Prandtl number. The advantage of the law of the "fourth" degree is shown for large Prandtl numbers for the calculation of heat transfer in tubes with turbulators; It is shown that for tubes with turbulators the proportionality coefficient in this law is much higher than in smooth tubes, which indicates an increased level of turbulence in them at the boundary of the viscous and buffer sublayers. The results of calculating heat transfer for large Prandtl numbers have shown that the relative heat exchange with increasing Prandtl number increases rather insignificantly, especially after $\operatorname{Pr}>10^{2}$; after $\operatorname{Pr}>10^{3}$ it almost stabilizes.

Keywords: modeling mathematical; heat exchange; intensification; turbulent; trumpet; flow; turbulizer; four-layered; boundary layer, the Prandtl test.

Данная работа непосредственно посвящена исследованию теплообмена при числах Рейнольдса, характерных для переходного режима течения в трубах, интенсифицированного поверхностными периодически расположенными турбулизаторами полукруглого поперечного сечения, поскольку в этом диапазоне ещё нет достаточно надёжных теоретических расчётных данных.

Для сравнения очень важно провести сравнительный анализ экспериментальных данных для труб с диафрагмами $[1,2]$.

Основное направление данной работы кратко можно охарактеризовать следующим образом:

- провести расчёты для относительно невысоких чисел Рейнольдса, характерных для переходного режима течения в трубах с турбулизаторами при различных числах Прандтля $(\operatorname{Re}=0,72 \div 50)$, где ещё нет надёжных теоретических расчётных данных, поскольку ранее расчёт проводился для более высоких чисел Рейнольдса [3-12];

- основное внимание уделяется специфическим аспектам расчётного исследования интенсифицированного теплообмена в переходной области, поскольку области с более высокими числами Рейнольдса ранее исследовались более ранних работах [3-12].

В области ламинарного течения интенсификация теплообмена малоинтересна [1, 2]. Однако, даже при больших числах Рейнольдса возможно существование ламинарного пограничного слоя на значительном 
удалении от входа в канал, поэтому характер взаимодействия ламинарного пограничного слоя с искусственными турбулизаторами и процесс теплообмена в условиях вязкостного и вязкостно-гравитационного режимов течения теплоносителя представляет самостоятельное значение.

Для области вязкостного режима теплоотдача в трубах с турбулизаторами может быть ниже, чем для гладких труб вследствие термического сопротивления застойных малоподвижных зон между турбулизаторами $[1,2]$.

Для области развитого вязкостногравитационного режима течения теплоносителя искусственные турбулизаторы потока мало влияют на уровень теплоотдачи $[1,2]$.

В переходном режиме течения искусственные турбулизаторы двояко воздействуют на характер потока в канале.

С одной стороны, они являются генераторами возмущений: генерируют дополнительные турбулентные возмущения к уже имеющимся в потоке естественным турбулентным возмущениям.

C другой стороны, турбулизаторы, достигая определённых относительных высот, взаимодействуют с турбулентными участками перемежающегося течения и способствуют быстрому развитию турбулентных возмущений, развившихся до размеров проходного сечения канала, так называемых «турбулентных пробок».

Чередование участков канала, имеющих как ламинарную, так и турбулентную структуру, т.е. перемежаемость течения в области перехода, вызывает перемену условий теплосъёма в каком-либо фиксированном сечении канала, поэтому имеют место колебания коэффициентов теплоотдачи.

При граничных условиях второго рода, т.е. при регулируемом подводе тепла, колебания коэффициента теплоотдачи проявляются в колебаниях температуры стенки, амплитуда которых зависит от нескольких факторов:

- предельных значений коэффициентов теплоотдачи, которые соответствуют турбулентному и ламинарному режимам течения в канале при фиксированном числе Рейнольдca;

- числа Струхаля, т.е. частоты колебаний;

- величины тепловой нагрузки;

- способа подвода теплоты; от значений и соотношений теплоёмкостей стенки и жидкости.

К внешним проявлениям взаимодействия с потоком теплоносителя искусственных турбулизаторов потока в области переходного течения можно отнести следующие:

- снижение значений осреднённых по времени коэффициентов теплоотдачи на участках трубы с ламинарным режимом течения;

- гораздо более ранняя генерация перемежаемости течения с одновременным сужением диапазона чисел Рейнольдса её существования;

- возникновение эффекта интенсификации теплообмена на участках со слаборазвитой структурой турбулентности потока;

- снижение критического числа Рейнольдса $\mathrm{Re}_{\mathrm{\kappa p}}$.

Детерминирование критического числа Рейнольдса было проведено в работах экспериментально $[1,2]$ тремя независимыми методами, давшими близкие значения:

1. по изменению законов осреднённой по времени местной теплоотдачи на конце обогреваемого участка канала;

2. по числу Рейнольдса, соответствующему максимуму пульсационной характеристики $\Delta T_{\max } / \Delta T_{\min }=\Delta \mathrm{Nu}_{\max } / \Delta \mathrm{Nu}_{\min }$ для сечения в конце обогреваемого участка;

3. по изменению закона сопротивления в изотермических режимах.

Снижение критического числа Рейнольдса $\mathrm{Re}_{\text {кр }}$ для труб с турбулизаторами имеет место при относительных диаметрах $d / D \leq 0,92$ и относительных шагах $t / D=0,5 \div$ 1,0 и может быть аппроксимировано следующим соотношением: $\left(\operatorname{Re}_{\text {кр }}\right)_{\text {турб }} /\left(\operatorname{Re}_{\text {кр }}\right)_{г л}=$ $(d / D)^{4,2}$.

Для течений со слаборазвитой турбулентностью эффект искусственной турбулизации потока заключается в следующем.

Турбулентное течение при малых числах Рейнольдса имеет малозаполненный профиль скорости, в отличие от развитого турбулентного течения.

Следовательно, температурный профиль будет менее заполненным, а основное термическое сопротивление в потоке при слаборазвитой турбулентности не будет локализовано в узком пристеночном слое, как для развитого турбулентного течения, а распределено в значительно более протяжённых пристеночных слоях, поэтому для достижения эффективной турбулизации потока необ- 
ходимо использовать турбулизаторы относительно больших высот, соизмеримых с толщиной пристеночного слоя, где срабатывается почти весь температурный напор.

Теоретическое исследование интенсифицированного теплообмена в области слаборазвитой турбулентности и переходной области проводилось в гораздо меньшей степени, чем для области развитого турбулентного течения.

В рамках данной работы именно этому аспекту уделяется специфическое внимание.

Например, в работах [3-12] расчётное исследование начинается с чисел Рейнольдса $\operatorname{Re} \geq 10^{4}$. В работах $[1,2]$ указывается, что имеются экспериментальные данные о высокой интенсификации теплообмена в областях с более низкими числами Рейнольдса $\mathrm{Re}=$ $2 \cdot 10^{3} \div 10^{4}$, где приводятся эмпирические данные по интенсифицированному теплообмену в данной области для различных чисел Прандтля: $\operatorname{Pr}=2 \div 50$.

Анализ экспериментальных данных различных исследователей, приведённых в $[1,2]$, показывает, что имеет место тенденция увеличения эффекта интенсификации теплоотдачи при увеличении относительной высоты турбулизаторов и увеличении относительного шага между турбулизаторами в переходной области, поскольку вышесказанное уменьшает значения критического числа Рейнольдса $\mathrm{Re}_{\mathrm{kp}}$, в то время как при развитом турбулентном течении капельной жидкости целесообразнее применять турбулизаторы относительно малой высоты и с относительно небольшими шагами.

Следовательно, интенсификация теплообмена в трубах в переходной области течения является перспективной и может быть выше интенсификации теплообмена для капельной жидкости в турбулентной области.

Вышесказанное обусловливает актуальность математического моделирования интенсифицированного теплообмена в трубах в областях со слаборазвитой турбулентностью и в переходных областях течения.

Были получены результаты расчёта интенсифицированного теплообмена в трубах с турбулизаторами для переходных режимов на основе многоблочных вычислительных технологий, основанных на решении факторизованным конечно-объёмным методом (ФКОМ) уравнений Рейнольдса, замыкаемых с помощью модели переноса сдвиговых напряжений Ментера, и уравнения энергии на разномасштабных пересекающихся структурированных сетках.

Были получены значения относительного теплообмена $\mathrm{Nu} / \mathrm{Nu}_{\text {гл }}$ в зависимости от числа Рейнольдса $\operatorname{Re}=2 \cdot 10^{3} \div 10^{4}$, а также сделан сравнительный анализ значений интенсифицированного теплообмена для больших, средних и малых относительных высот турбулизаторов.

Был сделан анализ аналогичных значений $\mathrm{Nu} / \mathrm{Nu}_{\text {гл }}$, но для средних относительных высот турбулизаторов.

Был сделан анализ значений для средних относительных высот, но для разных относительных шагов между турбулизаторами.

Анализ показал, что интенсификация теплообмена для относительно высоких выступов имеет место уже при относительно малых числах Рейнольдса, в то время как для относительно средних она возникает только при несколько бо́льших числах Рейнольдса, а для относительно малых выступов интенсификация теплообмена будет иметь место при числах Рейнольдса, превышающих числа Рейнольдса, характерных для переходного режима течения.

Для относительно средних выступов увеличение интенсификации теплообмена возникает в переходном режиме течения примерно с одних и тех же чисел Рейнольдca.

При переходном режиме течения для относительно малых шагов между турбулизаторами интенсификация теплообмена выше, чем для больших.

Влияние шага на интенсификацию теплообмена для турбулизаторов относительно средних высот таково, что интенсификация теплообмена при переходном режиме течения повышается при уменьшении относительного шага между турбулизаторами.

Влияние числа Прандтля на интенсификацию теплообмена для турбулизаторов при переходном режиме течения, как показывают результаты расчёта, таково, что бо́льшая интенсификация теплообмена имеет место при бо́льших числах Прандтля для относительно средних и больших высот турбулизаторов, а для относительно малых высот турбулизаторов интенсификация теплообмена снижается с увеличением числа Прандтля.

Вышеуказанное обусловливает использование в целях интенсификации теплообмена в переходной области течения относи- 
тельно высоких турбулизаторов и теплоносителей с большими числами Прандтля.

a)

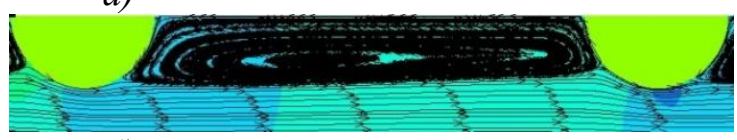

б)

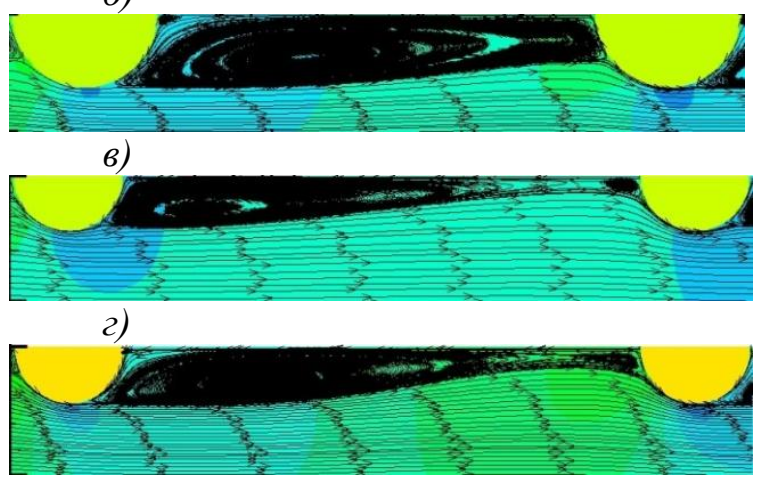

d)

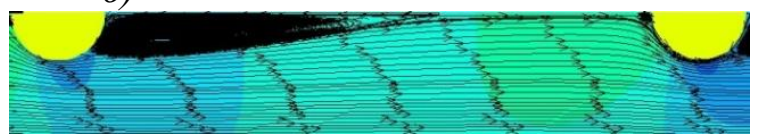

e)

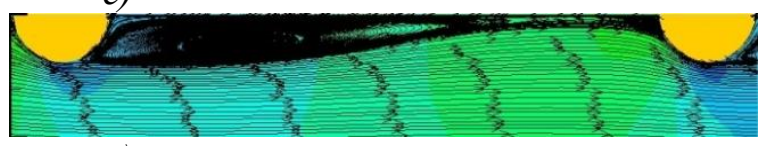

e)

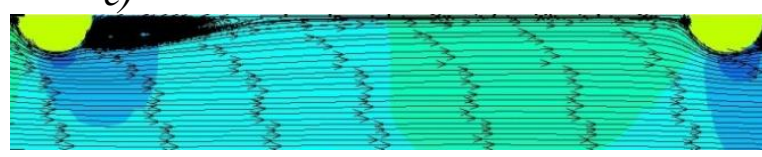

ж)

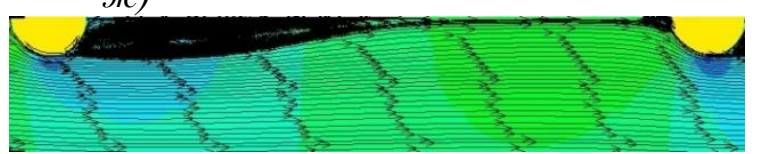

3)

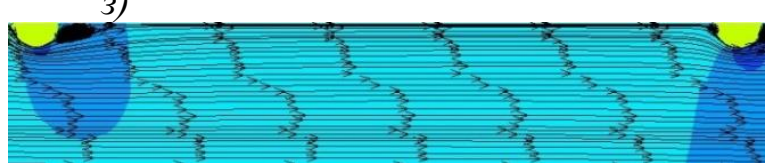

u)

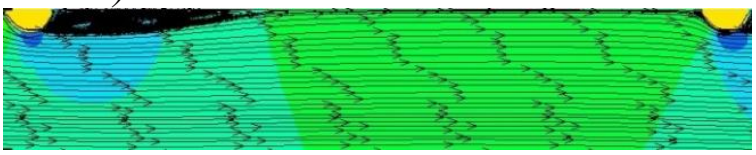

Рисунок 1 - Линии тока для трубы с турбулизаторами полукруглого поперечного сечения при:

a) $\operatorname{Re}=2 \cdot 10^{3}, d / D=0,875, t / D=0,496$; б) $\operatorname{Re}=10^{4}$, $d / D=0,875, t / D=0,496$; в) $\operatorname{Re}=2 \cdot 10^{3}, d / D=0,912$, $t / D=0,500 ;$ г) $\operatorname{Re}=10^{4}, d / D=0,912, t / D=0,500$;

д) $\left.\mathrm{Re}=2 \cdot 10^{3}, d / D=0,922, t / D=0,523 ; \mathrm{e}\right) \mathrm{Re}=10^{4}$, $d / D=0,922, t / D=0,523 ; \ddot{\mathrm{e}}) \mathrm{Re}=2 \cdot 10^{3}, d / D=0,943$, $t / D=0,497$; ж) $\operatorname{Re}=10^{4}, d / D=0,943, t / D=0,497$;

3) $\operatorname{Re}=2 \cdot 10^{3}, d / D=0,966, t / D=0,498$;

и) $\mathrm{Re}=10^{4}, d / D=0,966, t / D=0,498$.
Для качественного сравнения был проведён анализ соответствующих значений интенсифицированного теплообмена, полученных экспериментально для каналов с турбулизаторами прямоугольного, полукруглого и сегментного поперечных сечений $[1,2]$.

Сравнение расчётных и экспериментальных данных показывает, что они качественно сходны, поскольку имеет место низкая интенсификация теплообмена до критического числа Рейнольдса, после чего интенсификация теплообмена значительно возрастает.

Вышесказанное дополнительно косвенно верифицирует полученные в данной работе расчётные данные по теплообмену в трубах с турбулизаторами в переходной области течения.

В качестве иллюстрации на рис. 1 для некоторых случаев показаны линии тока между турбулизаторами полукруглого поперечного сечения, рассчитанные на основе реализованной в статье низкорейнольдсовой модели Ментера, характерные для переходного режима течения $\left(\operatorname{Re}=2 \cdot 10^{3} \div 10^{4} ; d / D=\right.$ $0,875 \div 0,983 ; \quad t / D=0,486 \div 1,987 ; \quad \operatorname{Pr}=$ $=0,72 \div 50)$. Представленные данные по линиям тока в трубах с турбулизаторами полностью соответствуют физическим представлениям реализуемых процессов $[6,13]$.

При $d / D=0,875$ и $t / D=0,496$ (рис. $1, \mathrm{a}$, б) при $\operatorname{Re}=2 \cdot 10^{3}$ имеет место закрытая впадина (классификация, разработанная в [3$12])$, в которой основной вихрь располагается почти равномерно в пространстве между турбулизаторами, а его центр немного смещён против потока относительно середины. При увеличении числа Рейнольдса до $\mathrm{Re}=$ $10^{4}$ имеет место деформация основного вихря: по потоку он ощутимо сжимается, а против потока немного увеличивается, причём центр вихря более смещается против потока.

При $d / D=0,912, t / D=0,500$ (рис. 1, в, г) при $\mathrm{Re}=2 \cdot 10^{3}$ основной вихрь деформирован по потоку, и имеет место полуоткрытая впадина, которая становится более выраженной при увеличении числа Рейнольдса Re $=10^{4}$.

При $d / D=0,922, t / D=0,523$ (рис. 1 , д, е) при $\operatorname{Re}=2 \cdot 10^{3}$ имеет место открытая впадина, но при увеличении числа Рейнольдса до $\operatorname{Re}=10^{4}$ открытая впадина плавно переходит в полуоткрытую.

При $d / D=0,943, t / D=0,497$ (рис. 1 , ё, ж) открытая впадина имеет место при всех 
числах Рейнольдса; при увеличении числа Рейнольдса от $\mathrm{Re}=2 \cdot 10^{3}$ до $\mathrm{Re}=10^{4}$ точка присоединения удаляется по потоку примерно от четверти до половины шага между турбулизаторами; точка отрыва обновлённого пограничного слоя располагается несколько далее против потока от последующего турбулизатора при увеличении числа Рейнольдca.

При $d / D=0,966, t / D=0,498$ (рис. 1, 3, и) также имеют место открытые впадины с чётко выраженными отрывами и присоединениями потока, но удаление по потоку точки присоединения турбулентного пограничного слоя при увеличении числа Рейнольдса от $\operatorname{Re}=2 \cdot 10^{3}$ до $\operatorname{Re}=10^{4}$ составляет от десятой части шага между турбулизаторами до его трети соответственно; точка отрыва обновлённого пограничного слоя располагается близко к последующему турбулизатору.

Полученные в работе расчётные данные по линиям тока в трубах с турбулизаторами находятся в полном соответствии с экспериментальными данными, приведёнными в монографиях $[1,2]$.

Проведённое в данной работе успешное моделирование теплообмена в трубах с турбулизаторами на базе низкорейнольдсовой модели Ментера при переходных числах Рейнольдса $\mathrm{Re}=2 \cdot 10^{3} \div 10^{4}$ обусловливает перспективное моделирование теплообмена в трубах с турбулизаторами данным методом и при относительно небольших числах Рейнольдса.

Таким образом, в статье было проведено математическое моделирование теплообмена в трубах с турбулизаторами полукруглого поперечного сечения при числах Рейнольдса, характерных для переходного режима течения, на основе многоблочных вычислительных технологий, основанных на решении факторизованным конечнообъёмным методом уравнений Рейнольдса и уравнения энергии и получено, что интенсификация теплообмена для относительно небольших чисел Рейнольдса $\mathrm{Re}=2 \cdot 10^{3} \div 10^{4}$ в широком диапазоне чисел Прандтля $\operatorname{Pr}=0,72 \div 50$, что может быть актуально в каналах.

В результате проведённых расчётов было выявлено влияние на интенсифицированный теплообмен при переходном режиме течения геометрических параметров канала и режима течения теплоносителя.

Установлено, что для турбулизаторов относительно средних и больших высот при переходном режиме бо́льшая интенсификация теплообмена имеет место при бо́льших числах Прандтля, а для относительно малых высот турбулизаторов интенсификация теплообмена снижается с увеличением числа Прандтля.

\section{СПИСОК ЛИТЕРАТУРЫ}

1. Калинин Э.К., Дрейцер Г.А., Ярхо С.А. Интенсификация теплообмена в каналах. - М.: Машиностроение, 1990. - 208 с.

2. Эффективные поверхности теплообмена / Э.К. Калинин, Г.А. Дрейцер, И.З. Копп и др. - М.: Энергоатомиздат, 1998. - 408 с.

3. Дрейцер Г.А., Исаев С.А., Лобанов И.Е. Расчёт конвективного теплообмена в трубе с периодическими выступами // Проблемы газодинамики и тепломассообмена в энергетических установках: Труды XIV Школы-семинара молодых ученых и специалистов под руководством академика РАН А.И. Леонтьева. - М.: МЭИ, 2003. - Т.1. - С. 57-60.

4. Дрейцер Г.А., Исаев С.А., Лобанов И.Е. Расчёт конвективного теплообмена в трубе с периодическими выступами // Вестник МАИ. - 2004. - Т. 11. - № 2. - С. 28-35.
5. Дрейцер Г.А., Исаев С.А., Лобанов И.Е. Расчёт конвективного теплообмена в трубе с периодически расположенными поверхностными турбулизаторами потока // Теплофизика высоких температур. - 2005. T. 43. - № 2. - С. 223-230.

6. Лобанов И.Е. Математическое моделирование интенсифицированного теплообмена при турбулентном течении в каналах: Дисс. ... докт. техн. наук. - М.: МАИ, 2005. $632 \mathrm{c.}$

7. Лобанов И.Е., Штейн Л.М. Перспективные теплообменные аппараты с интенсифицированным теплообменом для металлургического производства. В 4-х томах. Том I. Математическое моделирование интенсифицированного теплообмена при турбулентном течении в каналах с применением основных аналитических и численных методов. - М.: 
Издательство Ассоциации строительных ву3ов, 2009. -405 c.

8. Лобанов И.Е., Штейн Л.М. Перспективные теплообменные аппараты с интенсифицированным теплообменом для металлургического производства. В 4-х томах. Том II. Математическое моделирование интенсифицированного теплообмена при турбулентном течении в каналах с применением неосновных аналитических и численных методов. М.: Издательство Ассоциации строительных вузов, 2010. $-290 \mathrm{c}$.

9. Лобанов И.Е., Штейн Л.М. Перспективные теплообменные аппараты с интенсифицированным теплообменом для металлургического производства. В 4-х томах. Том III. Математическое моделирование интенсифицированного теплообмена при турбулентном течении в каналах с применением многослойных, супермногослойных и компаундных моделей турбулентного пограничного слоя. - М.: МГАКХиС, 2010. - 288 с.

10. Лобанов И.Е., Штейн Л.М. Перспективные теплообменные аппараты с интенсифицированным теплообменом для металлургического производства. В 4-х томах.
Toм IV. Специальные аспекты математического моделирования гидрогазодинамики, теплообмена, а также теплопередачи в теплообменных аппаратах с интенсифицированным теплообменом. - М.: МГАКХиС, 2011. $343 \mathrm{c}$.

11. Лобанов И.Е. Теоретическое исследование структуры вихревых зон между периодическими, поверхностно расположенными турбулизаторами потока прямоугольного поперечного сечения // Известия вузов. Авиационная техника. - 2011. - № 4. - С. 64 66.

12. Лобанов И.Е., Калинин Э.К. Теоретическое исследование, сопоставление с экспериментом линий тока и составляющих кинетической энергии турбулентных пульсаций в вихревых структурах в трубах с турбулизаторами // Отраслевые аспекты технических наук. - 2011. - № 12. - С. 4-15.

13. Численное моделирование вихревой интенсификации теплообмена в пакетах труб / Ю.А. Быстров, С.А. Исаев, Н.А. Кудрявцев, А.И. Леонтьев. - СПб: Судостроение, 2005. -398 c. 